\title{
What is the Diagnosis?
}

\section{CASE PRESENTATION}

The tracings below were obtained in long-term electrocardiographic monitoring by the Holter system.

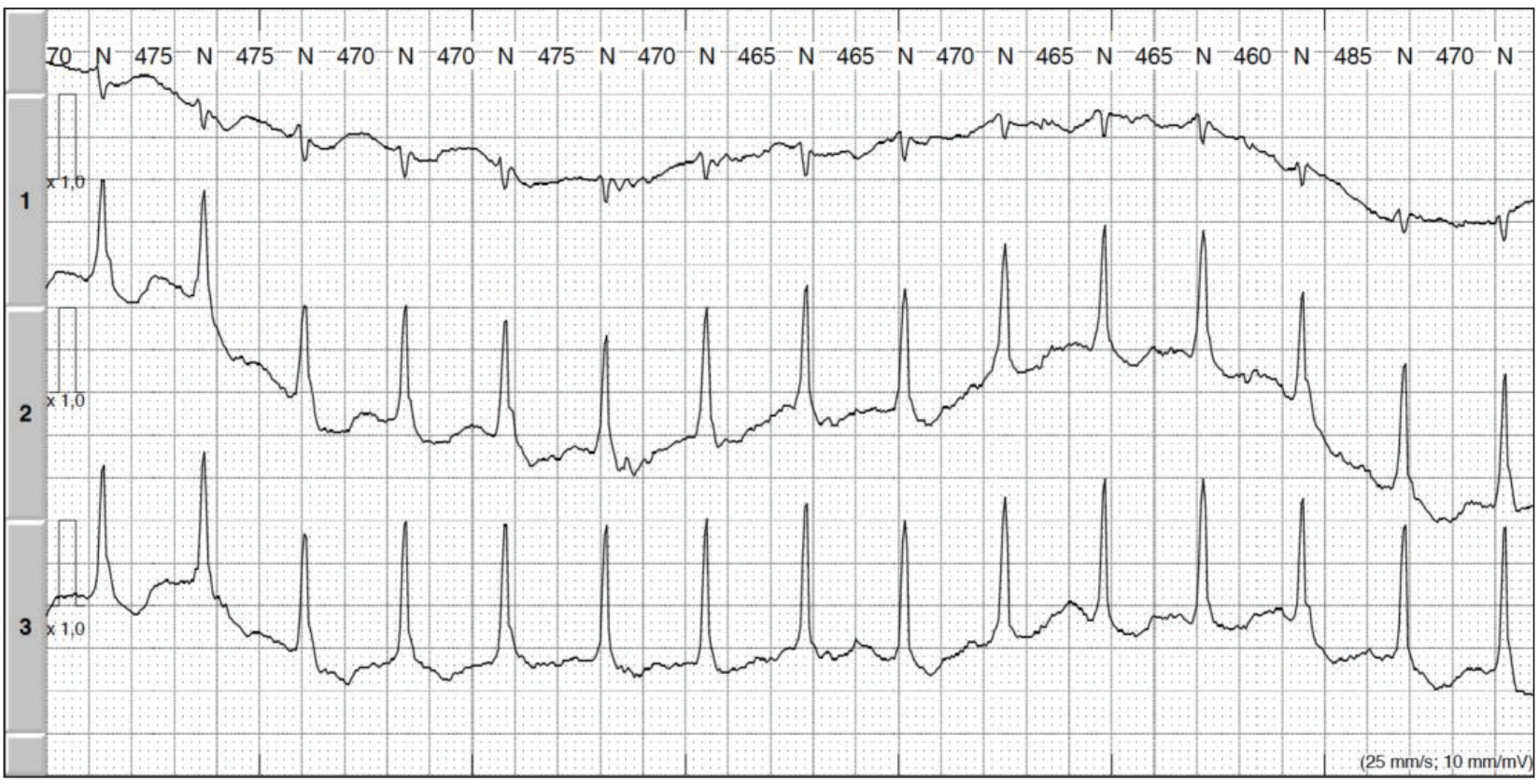

Figure 1. Tracings on 3 channels at a time of 24-hour electrocardiographic monitoring.

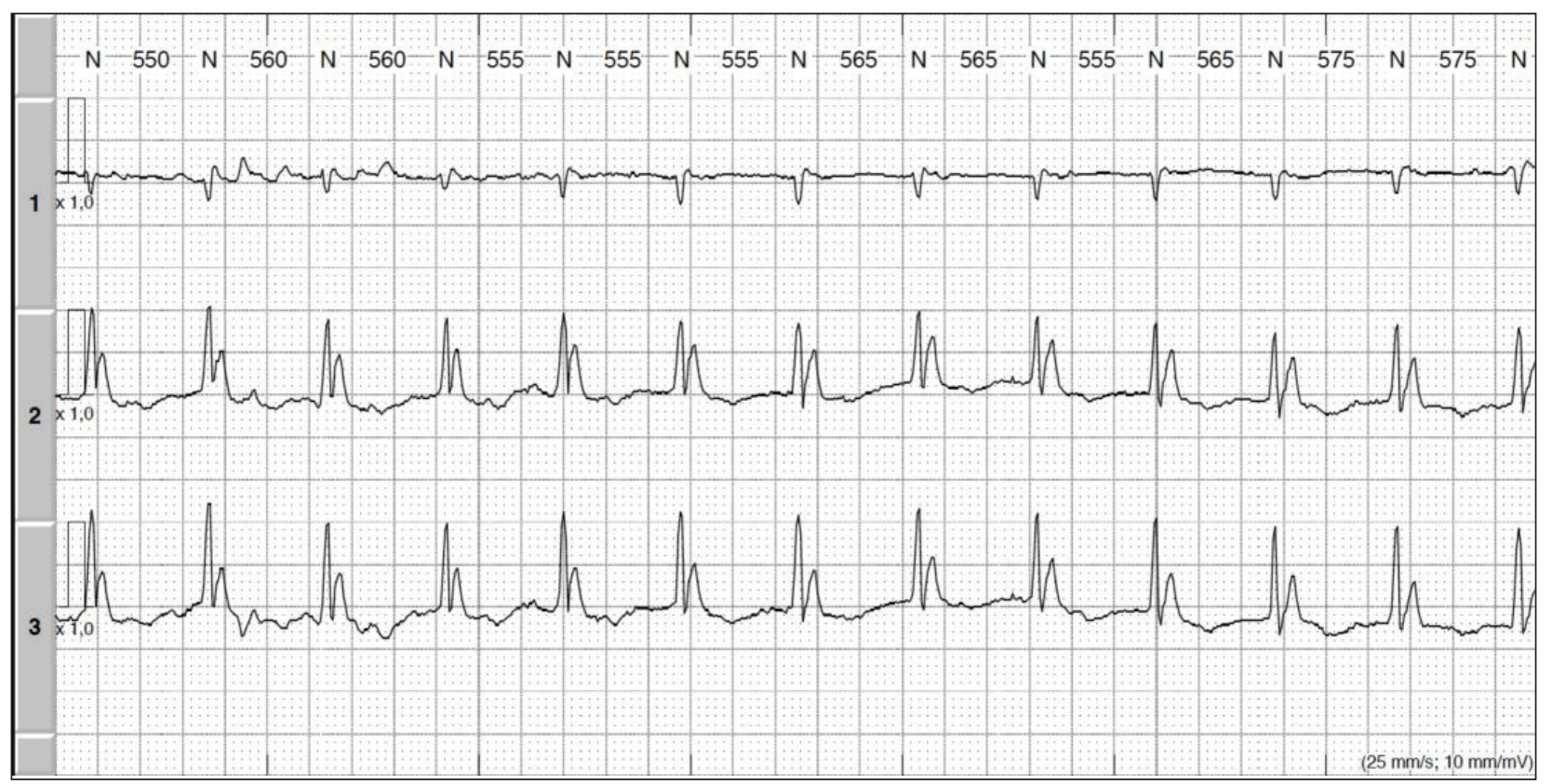

Figure 2. Tracings of the same exam obtained in a different moment. 


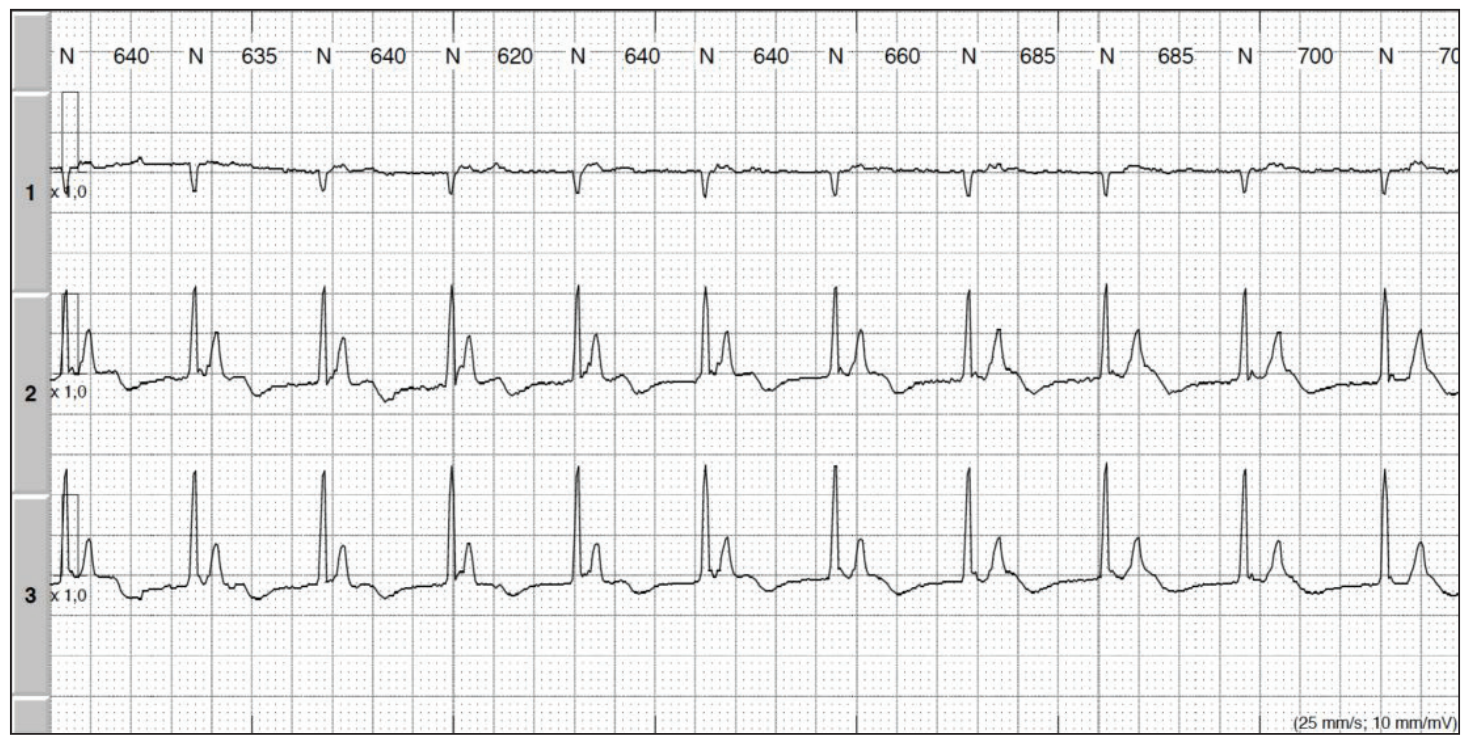

Figure 3. Heart rate unmasking after decrease heart rate.

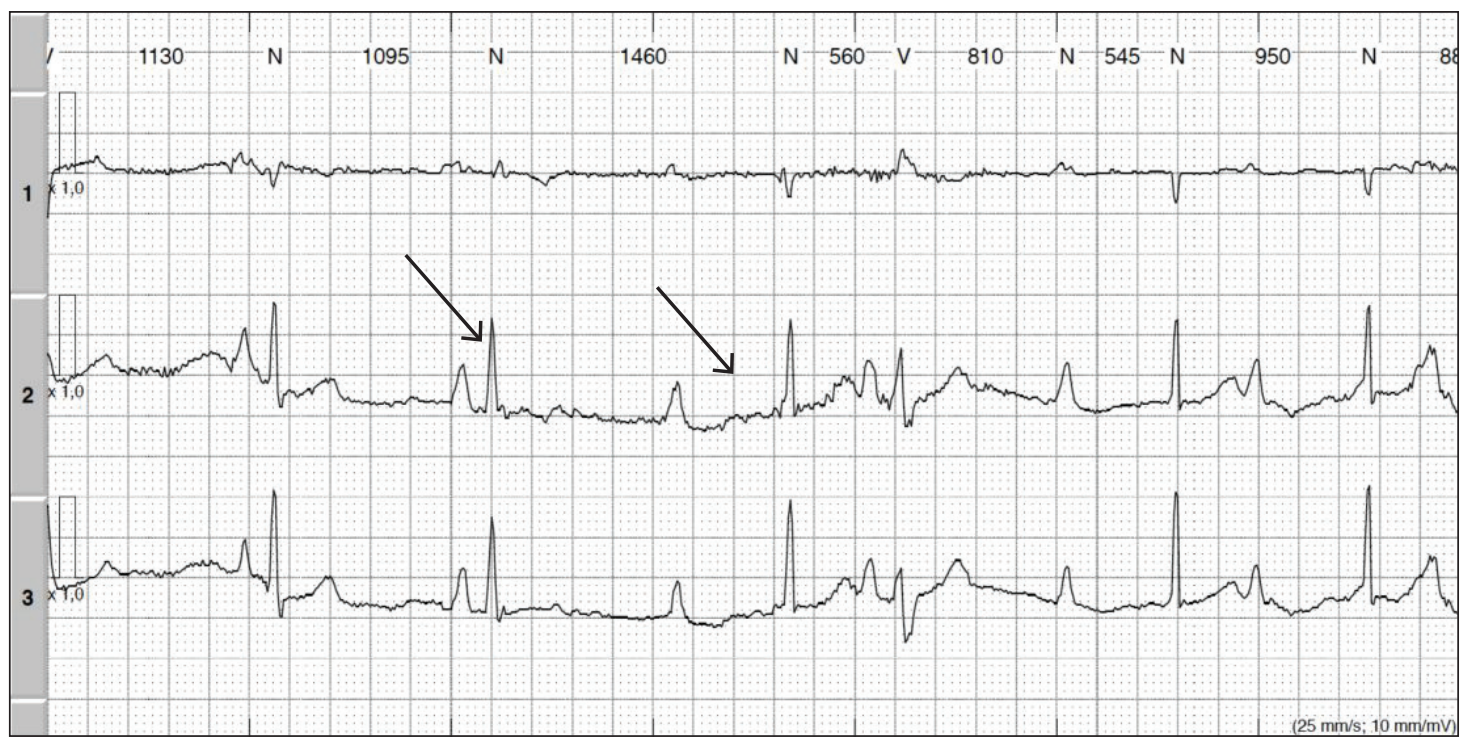

Figure 4. Electrocardiographic characterization of dual AV nodal pathway.

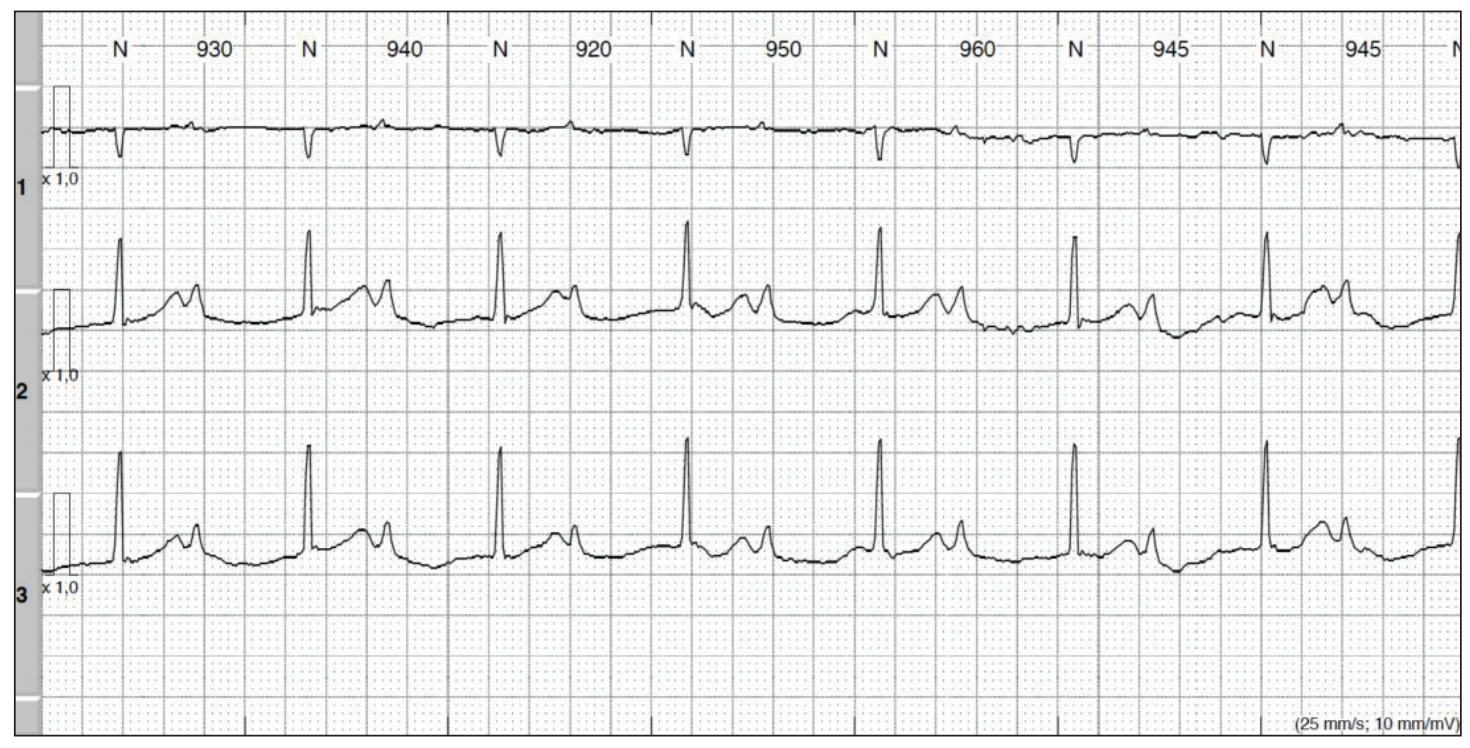

Figure 5. Sinus rhythm with first degree AV block and ultra-long PR. 


\section{DISCUSSION}

Figure 1 shows a regular tachycardia of narrow QRS complexes, with a cycle of $470 \mathrm{~ms}$, in which the presence of $\mathrm{P}$ waves cannot be characterized in the electrocardiogram. Several diagnostic possibilities can be inferred from the independent analysis of this tracing, from reentrant supraventricular tachycardia, such as nodal reentrant tachycardia, for example, to nonparoxysmal junctional tachycardia. Figure 2 shows that, despite the persistence of tachycardia, there is the appearance of "enlargement" of the QRS complexes. In Fig. 3 it is clear that what in Fig. 2 appeared to be a determining component of the QRS complex "enlargement" (simulating an intraventricular conduction disorder), corresponds to another independent electrical event, i.e.,P waves, which decouple from ventricular depolarization, in a cycle identical to the cycle of tachycardia itself. The presence of two independent tachycardia, a junctional and sinus tachycardia, could be inferred, occurring at that moment in the presence of isorhythmic atrioventricular (AV) dissociation. However, similar cycles presuppose the need to characterize the relationship of reciprocal interdependence of events in more extended monitoring. This is clear in Figs. 4 and 5 obtained at different moments. Figure 4 shows a sinus rhythm with preserved AV conduction in relation to 1:1 and regular PR interval $(160 \mathrm{~ms})$ in the first two cycles. In the third cycle there is an abrupt prolongation of the PR interval $(560 \mathrm{~ms}$ ), clearly characterizing the presence of dual AV nodal pathway (arrows): occurrence of conduction block in the fast pathway (beta pathway) by being reached in its refractory period and exclusive ventricular activation by a slow pathway (alpha pathway) with a first-degree AV block of high magnitude (PR interval $560 \mathrm{~ms}$ ). The third complex corresponds to a ventricular extrasystole. Figure 5 shows the moment of sinus rhythm with the persistence of the essential first-degree AV block.

Thus, it is evident that the tracings shown in Figs. 1,2 and 3 correspond to sinus tachycardia in AV junction relationship 1:1 with first-degree AV block of such great magnitude that the $\mathrm{P}$ waves are inscribed within the preceding $\mathrm{QRS}$ complexes when the sinus cycle is equal to the PR interval itself (Fig. 1). The determining electrophysiological element of this phenomenon is the presence of a dual $\mathrm{AV}$ nodal pathway in which the beta conduction is precarious, with predominant ventricular activation by the alpha pathway.

The literature describes clinical circumstances in which atrial systoles occurring with closed atrioventricular valves determine symptoms of heart failure and the presence of classic cannon $\mathrm{A}$ waves in the jugular venous pulse ${ }^{1,2}$. These characteristics correspond to the so-called "pseudo-pacemaker syndrome" (or pacemaker syndrome without pacemaker), that is one of the few situations in which definitive dual-chamber pacemaker implantation in supra-hisian first-degree atrioventricular block is required ${ }^{3}$ in order to provide adequate temporal synchronization of the atrial and ventricular systoles, eliminating the resulting symptoms.

\section{REFERENCES}

1. Kim YH, O'Nunain S, Trouton T, Sosa-Suarez G, Levine RA, Garan H, et al. Pseudo-pacemaker syndrome following inadvertent fast pathway ablation for atrioventricular nodal reentrant tachycardia. J Cardiovasc Electrophysiol. 1993;4(2):178-82. https://doi. org/10.1111/j.1540-8167.1993.tb01221.x

2. Barold SS, llercil A, Leonelli F, Herweg B. First-degree atrioventricular block. Clinical manifestations, indications for pacing, pacemaker management \& consequences during cardiac resynchronization. J Interv Card Electrophysiol. 2006;17(2):139-52. https://doi. org/10.1007/s10840-006-9065-X

3. Kusumoto FM, Schoenfeld MH, Barrett C, EdgertonJR, Ellenbogen KA, Gold MR, et al. 2018 ACC/AHA/HRS Guideline on the evaluation and management of patients with bradycardia and cardiac conduction delay. J Am Coll Cardiol. 2019;74(7): e51-e156. https://doi. $\operatorname{org} / 10.1016 / j$ j.jacc.2018.10.044

\section{AUTHORS}

Julio Cota Pacheco ${ }^{1, *}$, Beatriz Silvestre Knust ${ }^{1}$, Jonas Paes Leme' ${ }^{1}$, Hercilia Soares C. Arroyo dos Santos ${ }^{1}$

Pacheco JC (D) https://orcid.org/0000-0003-4934-4659

1.Clínica Cota Pacheco - Mogi das Cruzes (SP) - Brazil.

*Correspondence author: jcota@uol.com.br 